\title{
ENSINO DE CIÊNCIAS E PROCESSO DE SUBJETIVAÇÃO: A FORMAÇÃO DO CONCEITO CIENTÍFICO NA PSICOLOGIA DE VIGOTSKI ${ }^{1}$
}

\section{TEACHING SCIENCE AND PROCESS SUBJECTIVITY: THE FORMATION OF THE SCIENTIFIC CONCEPT IN PSYCHOLOGY VYGOTSKY}

\author{
${ }^{1}$ Luiza Oliveira, ${ }^{1}$ Rose Latini, ${ }^{1}$ Maria Bernadete Pinto dos Santos, ${ }^{1}$ Deborah Bernardes, \\ ${ }^{1}$ Raquel Guimarães, ${ }^{1}$ Roberto Andrade, ${ }^{1}$ Shayla Calil, ${ }^{1}$ Juliane Fernandes, ${ }^{2}$ Anderson \\ Rocha da Silva, ${ }^{1}$ Fátima de Paiva Canesin \\ ${ }^{1}$ Universidade Federal Fluminense \\ 2 Instituto Federal de Ciência, Tecnologia e Educação do Rio de Janeiro
}

\begin{abstract}
RESUMO
Este artigo, visando uma forma alternativa para o ensino de ciências, por meio da qual o aluno não desenvolveria um verbalismo vazio, mas a generalização necessária à formação de conceitos, traz a análise da formação de conceitos científicos, a partir do aporte da psicologia histórico-cultural. A relação do sujeito com o mundo é, na concepção vigotskiana, mediada por dois elementos, os instrumentos e os signos, que têm, respectivamente, as funções de "regular as ações sobre os objetos" e sobre o "psiquismo das pessoas". Este novo sentido dado à subjetividade - processo das formas culturais - afirma o homem historicamente situado. Esta é uma maneira de reapresentar o método da psicologia, pois inventa outro modo de intervenção no real. Para Vigotski, a formação da subjetividade é um processo que se engendra nas tensões das relações concretas, é nas atividades práticas, nas interações que devemos 'compreender' $o$ sujeito. Podemos, assim, entender como o método está relacionado à perspectiva de se pensar o conceito de subjetividade na obra de Vigotski, pois é a contradição, a tensão, o drama - como o autor gostava de dizer - entre a singularidade e a cultura que constituem o homem. Ao fazermos um estudo para pensar o entrelaçamento da subjetividade e do método em uma prática social específica - o ensino de ciências e a formação do conceito, é fundamental entendermos a diferença e a relação entre os conceitos científicos e os conceitos cotidianos.
\end{abstract}

Palavras-chave: conceito cotidiano; conceito científico; subjetividade; psicologia histórico-cultural.

\begin{abstract}
This article, seeking an alternative way for the teaching of science, through which the student does not develop only an empty verbalism but the necessary generalization to the formation of concepts, brings up the analysis of the formation of scientific concepts, from historical-cultural psychology theory. The relationship between the subject and the world is, according to Vygostky, mediated by two elements, the instruments and the signs. They have, respectively, the functions to regulate the actions upon objects and upon the psyche of people. This a new meaning of subjectivity - process of cultural forms - affirm the man historically situated. This is a way to present again the method of psychology, it invents another way to intervene in real. According to Vygotsky, the subjectivity formation's is a process that arises from the tensions in the concrete relations, it is in practical activities, in interactions that we 'understand' the subject. We can thus understand how the method is related to the perspective of thinking about the concept of subjectivity in the work of Vygotsky, it is the contradiction, the tension, the
\end{abstract}

\footnotetext{
${ }^{1}$ Este artigo é produto das pesquisas desenvolvidas pelo Grupo de Pesquisa Abordagem HistóricoCultural e as Práticas Sociais/UFF, com apoio da FAPERJ e do CNPq.
} 
drama - as the author liked to say - that constitute the man. By doing a study to consider the intertwining of subjectivity and method in a specific social practice science education and the formation of the concept- is critical to understand the difference and the relationship between scientific concepts and everyday concepts.

Key words: everyday concept; scientific concept; subjectivity; historical- cultural psychology.

\section{APRESENTAÇÃO DO TEMA}

Este artigo, visando uma forma alternativa para o ensino de ciências, por meio dos quais o aluno não desenvolveria apenas um verbalismo vazio e sim a generalização necessária à formação de conceitos, traz como tema a análise da formação de conceitos científicos, a partir do aporte da psicologia histórico-cultural.

A essência da teoria histórico cultural de Vigotski ${ }^{i}$ está na constatação de que o homem, diferente dos animais, interage com o meio sociocultural, em que está inserido, transformando-o e sendo por ele transformado,"num constate movimento de recriação e reinterpretação de informações, conceitos e significados" (REGO, 2013, p.55). A aquisição pelo sujeito das práticas sociais historicamente construída é elucida por Rego (2013, p. 55) quando descreve que

A partir de sua inserção num dado contexto cultural, de sua interação com membros de seu grupo e de sua participação em práticas sociais historicamente construídas, a criança incorpora ativamente as formas de comportamento já consolidadas na experiência humana.

Essa relação do sujeito com o mundo é, na concepção vigotskiana, mediada por dois elementos, os instrumentos e os signos, que têm, respectivamente, as funções de "regular as ações sobre os objetos" e sobre o "psiquismo das pessoas" (REGO, 2013 , p.50). Este reconhecimento do social na constituição do homem traz à teoria de Vigotski alguns questionamentos, que ao serem discutidos permitem uma análise epistemológica da obra do autor e a definição do que a psicologia histórico-cultural nomeia de social.

Após mais de três décadas, desde a primeira tradução das obras de Vigotski, tal como A Formação Social da Mente em 1984, muitos equívocos acompanham alguns estudos acerca da sua obra, tal como expõe Oliveira (1992). Aqui tratamos especificamente do conceito de social, que tem engendrado algumas apostas deterministas. Na discussão acerca da relação sujeito-objeto, Vigotski, fundamentado nas ideias marxistas, sobretudo na dialética, evidencia uma perspectiva não 
reducionista, pois não dá prevalência nem ao sujeito e nem ao meio. A subjetividade é processualidade, no discurso vigotskiano ${ }^{\mathrm{ii}}$, numa contraposição ao conceito cartesiano de sujeito, o que nos apresenta um homem inserido social e historicamente na cultura. Subjetividade é processo de subjetivação que se engendra nos conflitos, réplicas, contradições, tensões do mundo de significações concretas.

Este novo sentido dado à subjetividade - processo das formas culturais - afirma o homem historicamente situado. Esta é também uma maneira de reapresentar o método da psicologia, pois inventa outro modo de intervenção no real. Para Vigotski (2007), o método não se dá simplesmente pelo trato do fenômeno humano como fato, como coisa, como objeto. Como a formação da subjetividade é um processo que se engendra nas tensões das relações concretas, é nas atividades práticas, nas interações que devemos 'compreender' o sujeito.

Bakhtin (2009), filósofo da linguagem, que, tal como Vigotski, afirma a dialética marxista como forma de superação da dicotomia sujeito-realidade, diz que:

Compreender a enunciação de outrem significa orientar-se em relação a ela,
encontrar o seu lugar adequado no contexto correspondente. A cada palavra
da enunciação que estamos em processo de compreender, fazemos
corresponder uma série de palavras nossas, formando uma réplica. Quanto
mais numerosas e substanciais forem, mais profunda e real é a nossa
compreensão (BAKHTIN; VOLOCHINÓV, 2009, p. 137).

Dito isso, podemos entender que não há diagnóstico apartado da intervenção, na obra de Vigotski, pois para ele, compreender o outro é promover intervenção, é atividade criadora, em suas próprias palavras: 'A aceitação dessa proposição significa termos de encontrar uma nova metodologia para a experimentação psicológica" (VIGOTSKI, 2007, p. 62).

Fazendo um recorte e aproximando esta discussão do tema deste artigo, a pergunta que fazemos é 'como trazer a questão do sujeito histórico-cultural para a discussão do método em ensino de ciências?' Esta pergunta é relevante, pois, após quase duas décadas da aproximação entre a área de ensino de ciências e a psicologia histórico-cultural de Vigotski, há equívocos que vêm sendo perpetuados na área, um deles é o fato de as questões sociais serem tomadas como 'pano de fundo' sem nenhuma implicação epistemológica com a obra do autor. Além disso, os estudos vigostkianos acerca da formação do conceito científico não vêm sendo levados em consideração na área de ensino de ciências. Esta é a proposta que fazemos neste artigo - analisar como 
se dá a formação do conceito científico segundo Vigotski, trazendo à cena a subjetivação e o método na obra do psicólogo russo.

\section{SUBJETIVIDADE E MÉTODO NO ENSINO DE CIÊNCIAS - CONTRIBUIÇÕES DA PSICOLOGIA HISTÓRICO-CULTURAL DE VIGOTSKI}

Após vivenciarmos na área de ensino de ciências aportes que negam a subjetividade (fundamentos comportamentalistas) e epistemologias que, mesmo reconhecendo a importância do meio, dão prevalência ao sujeito, por meio das estruturas mentais (epistemologia genética), é importante analisar o lugar do sujeito histórico-cultural na constituição da formação do conceito científico nas práticas de aprendizagem.

Para tanto, veremos com o principal autor da psicologia histórico-cultural, Vigotski, aproxima subjetividade e método, a fim de pensar as práticas sociais, uma delas o ensino de ciências.

Segundo Vigotski, as funções psicológicas superiores, como todos os fenômenos, são processos em movimento e em mudança. A subjetividade é, portanto, processualidade, pois se produz no processo de individuação e diferenciação do homem inserido social e historicamente em uma cultura. E a sua compreensão só se dá pelo conhecimento das contradições que a constituem. A subjetividade, ou processo de subjetivação, se forma nos conflitos, nas réplicas, nas contradições, nas tensões, das relações concretas.

Podemos, assim, entender como o método está relacionado à perspectiva de se pensar o conceito de subjetividade na obra de Vigotski, pois é a contradição, a tensão, o drama - como o autor gostava de dizer - entre a singularidade e a cultura que constitui o homem (OLIVEIRA, 1992; WERNER, 2015).

Ao tratarmos da função constitutiva desses planos, entendemos, segundo Vigotski, que eles estão relacionados. Por exemplo, em se tratando da sociogênese e da microgênese, é esta articulação que, ao instituir a subjetividade, dá o caráter não determinista da teoria, pois não é o social que institui pelas marcas diretas das condições objetivas o sujeito, mas é o processo entre a fala social (fala exterior) e o sentido singular das apropriações do sujeito. Isto não diz respeito a uma singularidade a priori, mas aos encontros concretos que se especificam apesar e com as condições culturais e sociais. Este é o drama de que fala Vigotski, o sujeito não está aqui ou acolá, ele se produz e é produzido na convenção arbitrária estabelecida entre o significante e o 
significado que compõem um signo (fala exterior) - e o sentido - o que indica o significado da palavra para cada indivíduo (fala interior). Convenção arbitrária que acontece sempre com a mediação do outro das relações concretas, que dá sentido a como ser numa e a como pertencer a uma determinada cultura, isto é sim processo dialético no melhor sentido marxista, pois a fala interior, atravessada de apropriações microgenéticas, retorna em atividade criadora, o que evidencia a dialética na constituição do sujeito, num processo sem fim.

Vale ressaltar que Vigotski formulou seu método a partir da construção teóricometodológica de Karl Marx. Dito isso, é importante esclarecer alguns aspectos da teoria anteriormente citada. Marx foi criticado por alguns autores que interpretaram sua obra como determinista, visto que consideravam que este anularia o indivíduo - pois o mesmo seria fruto unicamente das condições históricas e sociais. Dessa forma, Marx teria uma tese limitada - já que não explicaria condições e desejos individuais, pois o Homem seria constituído apenas pelo meio. Em contraponto, a aposta presente nesse artigo é de que esse autor explicaria o Homem pela dialética - não o anulando, então. Marx delimitaria que a história é um meio do Homem se constituir, ou seja, ele é modificado pela sociedade na medida em que esta o transforma igualmente - dando ênfase à dialética.

Paralelamente, Vigotski acaba por ser atravessado pelas mesmas críticas que Marx sofre. A interpretação usualmente feita é de que Vigotski invalidaria o sujeito pois, supostamente, a cultura representaria o pólo ativo na constituição do Homem e este seria apenas passivo. Nesse sentido, outra concepção é a de que esse processo é uma dialética em que ambos modificam e são modificados, ou seja, não há um pólo unicamente ativo ou passivo.

Vale ressaltar que Vigotski ainda declara que o sujeito apenas se constitui com o outro, isto é, ele só se constitui como um eu, a partir da alteridade. Para além disso, é importante dizer que os signos e palavras são mediadores do processo anteriormente citado, visto que eles são instrumentos necessários para formação do Homem e, também, da sociedade. Cabe esclarecer que essas palavras não têm objetivo único de transmitir conhecimentos, elas são, sobretudo, um conjunto simbólico e articulado que é compartilhado por um determinado grupo. Portanto, Vigotski não pode ser considerado um verbalista. 


\begin{abstract}
Além da atividade reprodutiva, é fácil notar no comportamento humano outro gênero de atividade, mais precisamente a combinatória ou criadora. Quando, na imaginação, esboço para mim mesmo um quadro do futuro, digamos, a vida do homem no regime socialista, ou o quadro de um passado longínquo de vida e luta do homem pré-histórico, em ambos não reproduzo as impressões que tive de sentir alguma vez. Não estou simplesmente restaurando a marca de excitações anteriores que chegaram ao meu cérebro, pois nunca vi, de fato, nem esse passado nem esse futuro. Apesar disso, posso ter a minha ideia, a minha imagem, o meu quadro (VIGOTSKI, 2009, p. 13).
\end{abstract}

Esta concepção acerca da formação da subjetividade (ou subjetivação), na obra de Vigotski, diz sobre a relação entre duas categorias fundamentais na obra dele, pensamento e linguagem. Nossa interação com o mundo e com as pessoas se dá, segundo Vigotski (2003), através dos instrumentos e signos. É o desenvolvimento dessa relação entre pensamento e linguagem que proporciona a aprendizagem.

Todas as funções psíquicas de grau mais elevado são processos mediados e os signos são os meios fundamentais utilizados para os dominar e orientar. O signo mediador é incorporado na sua estrutura como parte indispensável a bem dizer fulcral do processo total. $\mathrm{Na}$ gênese do conceito, esse signo é a palavra, que a princípio desempenha o papel de meio de formação de um conceito, transformando-se mais tarde em símbolo (VIGOTSKI, 2003, p. 70).

A partir dessa fala de Vigotski, levando em conta que a constituição do homem se dá na relação com o meio histórico-cultural, a mediação ocorrerá através do contato com outros homens concretos, os quais também inseridos no mundo dos signos, nos permitirão também essa imersão, sendo assim possível desenvolver o pensamento verbal e a linguagem racional.

Apesar de em algum momento o pensamento tornar-se verbal, isso não significa que a linguagem é uma simples transcrição do pensamento. $O$ pensamento e a linguagem têm estruturas diferentes. Enquanto o pensamento não é dividido em fragmentos, a linguagem é. Quando pensamos em uma cabana, pensamos no todo, apenas no pensamento verbal que colocamos a janela de vidro, a porta de madeira, a chaminé de pedras...

Ao fazermos um recorte para pensar o entrelaçamento da subjetividade e do método em uma prática social específica - o ensino de ciências e a formação do conceito, é fundamental, segundo Vigotski (2003), entendermos a diferença e a relação entre os conceitos científicos e os conceitos prévios (conceitos cotidianos) ) $^{\mathrm{iii}}$, que, de acordo com o autor, são processos que se encontram relacionados e mutuamente influenciáveis. 
Para o autor os conceitos cotidianos são aqueles construídos pela criança no seu dia a dia e que se generalizam, isto é se tornam mais complexos, a partir do conceito científico. Usando um exemplo do próprio autor, quando a criança aprende a palavra "flor" e depois a palavra "rosa" ela usa as duas igualmente, sem distinção de significado, sem subordinar uma à outra. Somente quando o conceito "flor" se generaliza, a relação entre "flor" e "rosa" se modifica na mente da criança. Neste sentido, o significado dos conceitos científicos se explicita na sua relação com os conceitos cotidianos e se definem a partir dele. Assim, para Vigotski (2003), o desenvolvimento de um conceito científico é descendente e dos conceitos espontâneos ascendente, para uma forma cada vez mais elaborada.

Esse entendimento permite que no ensino de ciências se supere uma concepção equivocada de construção de conhecimentos, fortemente presente nas práticas de ensino nas décadas de 1950 a 1990, nas quais era necessário se conhecer os conceitos cotidianos dos alunos para poder negá-los ou superá-los, como se esse conceito fosse algo que impede a construção de conceitos científicos.

Deste modo, entendendo como essa relação entre conceitos cotidianos e conceitos científicos se dá, podemos compreender e encontrar de fato algum caminho no ensino de ciências, levando em conta que a mediação determina o destino do desenvolvimento mental do sujeito e consequentemente o seu processo de aprendizagem.

Vigotski (2003) discute as várias abordagens da formação do conceito científico pela réplica entre respostas dadas por diferentes aportes teóricos a duas perguntas: “ $O$ que acontece na mente das crianças com os conceitos científicos que lhe são ensinados na escola?" e "Qual é a relação entre a assimilação da informação e o desenvolvimento interno de um conceito científico na consciência da criança?” A primeira resposta, ainda predominante na área de ensino de ciências, é que os conhecimentos científicos seriam assimilados já prontos, não passando por nenhum desenvolvimento. Esta resposta é expressada por uma escola de pensamento que afirma que o conhecimento aprendido não tem nenhuma história anterior e/ou interna ao homem. Esta é uma perspectiva da psicologia comportamentalista, que na área de ensino de ciências teve grande predomínio entre as décadas de 1950 e de 1970. Sob o aporte teórico e prático da psicologia de Skinner, a área de ensino de ciências afirmava a aprendizagem fundamentada nas contingências ambientais e numa completa negação do sujeito. Era tempo dos grandes programas de ensino de ciências e de seus ideais para formar cientistas: PSSC (comitê de estudos de ciências físicas), BSSC (comitê de estudos de 
ciências biológicas), entre outros. Tempos de Pavlov, Watson e Skinner e de uma psicologia do consenso, da adaptação e do assujeitamento.

Vigotski (2003) critica esta concepção dizendo que um conceito é mais do que uma soma de associações formadas pela memória e que o ensino empirista de conceitos à criança é inútil, pois resultaria apenas em um verbalismo vazio. Um conceito é um ato de generalização e à medida que o intelecto da criança se desenvolve, a generalização também acompanha esse desenvolvimento e isso levará à formação de conceitos científicos.

\begin{abstract}
Em qualquer idade, um conceito encarnado numa palavra representa um acto de generalização. Mas o significado das palavras evolui e, quando a criança aprende uma nova palavra, o seu desenvolvimento mal começou: a princípio a palavra é uma generalização do tipo mais primitivo; à medida que o intelecto da criança se desenvolve é substituída por generalizações de tipo cada vez mais elevado - processo este que acaba por levar à formação dos verdadeiros conceitos. (VYGOTSKY, 2003, p.112)
\end{abstract}

Coforme Vigotski, a segunda resposta não nega o processo de desenvolvimento mental da criança, mas coloca a formação de conceitos científicos e cotidianos em um mesmo patamar, desenvolvendo-se da mesma forma. Piaget, de acordo com Vigotski (2003), responde a essa pergunta dizendo que os conceitos cotidianos seriam formados mediante os próprios esforços mentais da criança e que os científicos seriam influenciados pelos adultos.

Lev Vigotski, em seu livro Pensamento e Linguagem (2003), critica alguns pontos dessa teoria ao notar que para Piaget as marcas da mentalidade da própria criança estão presentes apenas nos conceitos cotidianos. Piaget não vê relação entre esses conceitos e os científicos, um elo que os una, o que faz com que o pensamento cotidiano precise ser combatido para este autor.

Os conceitos se formam e se desenvolvem sob condições internas e externas totalmente diferentes. A forma como a criança aprende na escola, em sala de aula, é diferente da forma como ela aprende através de sua própria experiência, no dia a dia. Os conceitos científicos e cotidianos diferem quanto a sua relação com a criança e da atitude da criança para com os objetos e por isso seu desenvolvimento é diferente.

Para Vigotski, o desenvolvimento dos conceitos cotidianos e científicos fariam parte de um único processo, e esse seria o desenvolvimento da formação do conceito, em que ambos seriam relacionáveis e se influenciariam mutuamente. Esse único processo não se daria por relações de conflito das formas de compreensão antagônicas e exclusivas entre si, como Piaget acreditava, mas se daria por afetação entre condições 
externas e internas variáveis, mas que não deixam de ser um processo. É de suma importância explicar a relação entre os conceitos cotidianos e científicos para assim ser possível entender o tema.

Vigotski ressalta no capítulo "O desenvolvimento dos conceitos científicos na infância", do livro Pensamento e Linguagem (2003), o quanto o professor é importante para a formação desses conceitos na aprendizagem. Ele atuaria como um mediador do processo em que o ensino formal é uma das fontes dos conceitos que a criança da idade escolar precisa aprender. Logo, percebe-se que o ensino e o professor influenciam diretamente no destino do desenvolvimento mental da criança.

É nossa tese que os rudimentos de sistematização primeiro entrem na mente da criança, por meio de seu contato com os conceitos científicos, e são depois transferidos para os conceitos cotidianos, mudando a estrutura psicológica de cima para baixo (...) um conceito supra-ordenado implica a existência de uma série de conceitos subordinados,e pressupõe também uma hierarquia de conceitos de diferentes níveis de generalidade. (VIGOTSKI, 2003, p. 116).

Pensando o ensino de ciências, tomando a psicologia de Vigotski como referência, podemos entender que a generalização do conceito científico não é oposta à contextualização, à concretude do saber cotidiano, mas se constituem dialeticamente. A aprendizagem é a elaboração de uma forma cada vez mais complexa do particular.

\footnotetext{
Particular (pensamento sincrético, imaginação, concepção prévia) que não é obstáculo ao conhecimento, mas está em permanente relação com o conhecimento generalizante (conceito supra-ordenado) e é isso que permite a Generalização tão cara para o desenvolvimento de uma concepção científica. Logo, tal como afirma Vigotski, a consciência reflexiva chega à criança através dos conhecimentos científicos e depois se transfere aos conceitos espontâneos (OLIVEIRA E OUTROS, 2015, pp. 33-4).
}

Ao analisarmos a teoria de Vigotski (2003), percebemos o quanto podemos mudar a forma pela qual os conceitos vêm sendo ensinados nas escolas atualmente. Um conhecimento baseado em verbalismo é infrutífero, já que percebemos que muitos alunos sequer lembram o que estudaram minutos depois de terminarem uma avaliação. Alternativas precisam ser pensadas, mas isso não é uma tarefa fácil. Quando uma mudança é proposta, normalmente é recebida com desconfiança, receio e muitos professores têm medo de sair do que foi previamente programado, achando que isso irá prejudicar o aprendizado e seus cronogramas de alguma forma. 


\section{CONSIDERAÇÕES FINAIS}

Fazer estudos sobre a formação e o desenvolvimento dos conceitos é fundamental para pensarmos e analisarmos como esse tema está diretamente relacionado à forma que as práticas em ensino de ciências se constituem atualmente. Podemos considerar que o estudo desse tema traz implicações para a área de ensino de ciências, visto que este é o principal objetivo de suas pesquisas. Estudos específicos acerca das contribuições da psicologia histórico-cultural trazem à cena ações alternativas no ensino de ciências, pois, de fato, este campo de saber possibilita pensar as relações entre os saberes cotidianos e os saberes científicos de forma dialética, para além da contraposição entre ambos, que tradicionalmente marca os estudos da área de ensino de ciências sobre o tema.

\section{REFERÊNCIAS}

BAKHTIN, M./VOLOCHINÓV, V. Marxismo e Filosofia da Linguagem. 13 edição. São Paulo: HUCITEC, 2009.

OLIVEIRA, L.R. ; LATINI, R.M. ; SANTOS, Maria Bernadete Pinto dos ; CANESIM, Fátima de Paiva. A contextualização no ensino de química: uma análise à luz da filosofia da linguagem de Bakhtin. Revista Ciências \& Ideias, v. 6, p. 29-45, 2015. OLVEIRA, M.K. Temas em Psicologia: Vygotsky - alguns equívocos na interpretação de seu pensamento. Cad. Pesq. São Paulo, n. 81, p. 67-74, maio de 1992.

REGO, T.C. Vygotsky: umaperspectiva histórico-cultural da Educação. Petrópolis: Vozes, 2013.

SAWAIA, B B. Psicologia e desiguladade social: um areflexão sobre liberdade e transformação social. Psicologia Sociedade, Belo Horizonte, 2009; 21(3): 364-372. VIGOTSKI, L. El instrumento y el signo en dessarrollo del nino. Obras Escogidas VI. Madrid: Editorial Pedagógica, 2013a.

Doctrina de lãs emociones. Investigación histórico-psicológica. Obras Escogidas - VI. Madrid: Editorial Pedagógica, 2013b.

Imaginação e Criação na Infância. São Paulo: Ática, 2009.

A Formação Social da Mente. 7 edição. São Paulo: Martins Fontes,

2007.

Pensamento e Linguagem. 2 edição. São Paulo: Martins Fontes, 2003. Manuscrito de 1929. Educação \& Sociedade, ano XXI, n71, Julho/00

Teoria e Método em Psicologia. São Paulo: Martins Fontes, 1996.

WERNER, J. A relação linguagem, pensamento e ação na microgênese das funções psíquicas superiores. Fractal: Revista de Psicologia, v. 27, n. 1, p. 33-38, jan.-abr. 2015. 


\footnotetext{
' A grafia do nome do autor Vigotski está de acordo com as discussões atuais da Sociedade Brasileira de Psicologia do Desenvolvimento. No entanto, será respeitado quando houver citações de textos em que a grafia do nome do autor está diferente.

ii Não há nos textos de Vigotski o aparecimento do termo subjetividade, mas defendemos, tal como outros estudiosos da obra do autor (SAWAIA, 2009), que o conceito está instituído quando Vigotski fala sobre a criatividade humana mesmo que sob as determinações sociais (SAWAIA, 2009).

iii Usaremos neste artigo a denominação conceito cotidiano, em vez de conceito prévio ou conceito espontâneo, este último utilizado por Vigotski no texto do livro Pensamento e Linguagem (2003) A referência ao termo conceito espontâneo se dá na obra de Vigotski, pois o autor parte da réplica à Piaget, que usava o termo, devido as suas fundamentações epistemológicas.
} 